\title{
Association between diuretic use and the risk of vertebral fracture after stroke: a population-based retrospective cohort study
}

Shu-Man Lin ${ }^{1+}$, Shih-Hsien Yang ${ }^{1,2+}$, Chih-Yung Wang ${ }^{3+}$ and Huei-Kai Huang ${ }^{2,3^{*}}$ (D)

\begin{abstract}
Background: Stroke is a major risk factor for osteoporosis and fractures. No study has evaluated the association between diuretic use and risk of vertebral fracture in stroke patients, although a considerable proportion of stroke patients are prescribed diuretics for hypertension. Our study aimed to investigate whether treatment with thiazides or loop diuretics affects the risk of vertebral fracture after stroke.

Methods: A population-based propensity score-matched retrospective cohort study was conducted using the Taiwan National Health Insurance Research Database. Patients with a new diagnosis of stroke between 2000 and 2011 were included. After propensity score matching, 9468 patients were included in the analysis of the effect of thiazides, of who 4734 received thiazides within 2 years after stroke. To analyze the loop diuretic effect, 4728 patients were included, of who 2364 received loop diuretics. Cox proportional hazards regression models were used to calculate hazard ratios (HRs) of vertebral fractures among patients according to thiazide or loop diuretic use within 2 years following stroke. Sensitivity analyses based on the duration of thiazide or loop diuretic use were further conducted.

Results: There was no significant difference in vertebral fracture risk between thiazide users and non-users (adjusted $\mathrm{HR}[\mathrm{aHR}]=1.14,95 \%$ confidence interval $[\mathrm{Cl}]=0.88-1.47, p=0.316)$. Loop diuretic users had a significantly higher vertebral fracture risk than non-users $(\mathrm{aHR}=1.45,95 \% \mathrm{Cl}=1.06-1.98, p=0.019)$. However, the sensitivity analysis revealed that short-term thiazide use (exposure duration $<90$ days within 2 years after stroke) significantly increased the risk of vertebral fracture versus non-use ( $a \mathrm{HR}=1.38,95 \% \mathrm{Cl}=1.02-1.88, p=0.039)$. Only short-term loop diuretic users had significantly higher risk of vertebral fracture $(a H R=1.56,95 \% \mathrm{Cl}=1.11-2.20, p=0.011)$. The other two subgroups with longer exposure duration in analyses for both thiazides and loop diuretics revealed no significant effect.
\end{abstract}

Conclusions: Short-term thiazide or loop diuretic use was associated with an increased risk of vertebral fracture after stroke. Further prospective clinical trials are required to confirm this finding.

Keywords: Stroke, Vertebral fracture, Diuretics, Thiazides, Loop diuretics, Cohort study

\footnotetext{
*Correspondence: drhkhuang@gmail.com

'Shu-Man Lin, Shih-Hsien Yang and Chih-Yung Wang contributed equally to this work.

${ }^{2}$ School of Medicine, Tzu Chi University, No.701, Sec. 3, Chung Yang Rd.

Hualien 97002, Taiwan

${ }^{3}$ Department of Family Medicine, Buddhist Tzu Chi General Hospital, No. 707,

Sec. 3, Chung Yang Rd., Hualien 97002, Taiwan

Full list of author information is available at the end of the article
}

(c) The Author(s). 2019 Open Access This article is distributed under the terms of the Creative Commons Attribution 4.0 International License (http://creativecommons.org/licenses/by/4.0/), which permits unrestricted use, distribution, and reproduction in any medium, provided you give appropriate credit to the original author(s) and the source, provide a link to the Creative Commons license, and indicate if changes were made. The Creative Commons Public Domain Dedication waiver (http://creativecommons.org/publicdomain/zero/1.0/) applies to the data made available in this article, unless otherwise stated. 


\section{Background}

The most common sites of osteoporotic fracture are the vertebrae [1]. Previous research illustrated that the overall prevalence of vertebral fracture was approximately $13 \%$, including prevalence as high as $20 \%$ in people aged $\geq 70$ years [2]. Vertebral fracture is associated with significant disability, morbidity, and mortality [3-5]. Stroke is a major risk factor for osteoporosis and fracture [6]. Previous studies indicated that bone mineral density (BMD) remarkably decreased soon after stroke [7, 8]. Both decline in BMD and increase in the risk of falls elevate the risk of fractures following stroke $[9,10]$.

Hypertension is a very common comorbidity observed in patients with stroke. Previous studies revealed that $79 \%$ of ischemic stroke patients and $85 \%$ of hemorrhagic stroke patients have hypertension as a comorbidity $[11,12]$. Both thiazides and loop diuretics have been widely used for the treatment of hypertension [13-15]. Thiazides, in addition to reducing blood pressure, can modulate calcium homeostasis, thus effectively preserve BMD [16]. Previous studies revealed that thiazides not only reduce urinary calcium excretion but also directly stimulate osteoblast differentiation and bone mineral formation [17]. However, thiazides can also induce hyponatremia, which was suggested by several studies to be associated with increased fracture risk [18-21]. Loop diuretics were reported to increase urinary calcium excretion [22], and they could theoretically lower BMD, which is a known risk factor for osteoporotic fracture. However, the results concerning the association of loop diuretics and BMD were inconsistent among studies reported [23-25]. In addition, loop diuretics may potentially increase the risk of falls [26].

Several studies evaluated the association of diuretic use and hip fracture risk [27-32]. However, only a few studies have evaluated the vertebral fracture risk [33-37], although vertebral fracture was the most common type of osteoporotic fracture, and it can also cause significant morbidity and mortality, and a considerable socioeconomic burden. Moreover, no current study on this issue is based on post-stroke patients, which is a specific population prone to developing fracture due to declining BMD and an increased risk of falls as mentioned above. The evidence on whether thiazide or loop diuretic use influences the risk of vertebral fracture in post-stroke patients is still insufficient. Therefore, we conducted a population-based propensity score-matched retrospective cohort study to investigate whether thiazide or loop diuretic use affected the risk of vertebral fracture after stroke.

\section{Methods}

\section{Data sources}

The data of this present study were obtained from the Taiwan National Health Insurance Research Database. In
1995, Taiwan began a National Health Insurance (NHI) program, which is a single-payer program administered by the government, to finance health care for all residents in Taiwan. Approximately 99\% of the Taiwanese population was covered and 97\% of the hospitals and clinics had contracts with the NHI program in Taiwan $[38,39]$. We analyzed a representative database of 1000,000 people, called the Longitudinal Heath Insurance Database (LHID), which was randomly sampled from all NHI beneficiaries in the registry of year 2000 in Taiwan by the National Health Research Institute (NHRI) for research purposes. The LHID included comprehensive information on the sampled insured people, such as demographic data, dates of clinical visits or hospitalization, diagnostic codes, expenditure amounts, and details of prescriptions [40]. The NHRI reported no statistically significant difference in age, sex, or medical costs between the sampling cohort in LHID and all NHI beneficiaries in Taiwan [41]. After receiving NHRI approval, we used the LHID to conduct our study. Personal identification information was encrypted before releasing the research database from the NHRI to protect patient privacy and data security. This study was approved by the Institutional Review Board of Tzu Chi Medical Center.

\section{Study population}

All patients diagnosed with new-onset stroke between January 2000 and December 2011 comprised the study population. As our previous study also focused on stroke patients [42], we used the primary discharge diagnosis of stroke (International Classification of Diseases, 9th Revision, Clinical Modification [ICD-9-CM] codes 430-437) to identify these patients. The index date was defined as the date of stroke diagnosis, and index hospitalization was defined as hospitalization for new-onset stroke.

As our previous study evaluated the association between thiazides and hip fracture [43], we retrieved all prescription data for thiazides and loop diuretics within 2 years after the diagnosis of new-onset stroke to evaluate the association between diuretic use and the risk of vertebral fractures. Patients who were prescribed thiazides within 2 years after stroke were defined as the thiazide cohort, those who were prescribed loop diuretics comprised the loop diuretic cohort, and those who had not been prescribed any thiazides or loop diuretics were defined as the comparison cohort. To further evaluate the effects of short- and long-term exposure to diuretics, both the thiazide and loop diuretic cohorts were divided into three subgroups [43]: patients with exposure duration of 1-90, 91-365, and > 365 days within 2 years following stroke.

The exclusion criteria were 1) age < 20 years; 2) history of stroke before the study period of 2000-2011;3) 
history of previous vertebral fracture before stroke; 4) concurrent diagnosis of vertebral fracture during index hospitalization; 5) death during index hospitalization, and 6) use of both thiazides and loop diuretics within 2 years after stroke (Fig. 1).

\section{Primary outcome and covariates}

The ICD-9-CM codes 733.13, 805.x, and 806.x were used to identify inpatients and outpatients who developed vertebral fractures within 2 years after stroke. All the study subjects were followed up from index date until a new diagnosis of vertebral fracture, withdrawal from the LHID database, or the end of the 2-year follow-up period after stroke. A previous research validated the ICD-9-CM codes for bone fractures, including vertebral fracture, and confirmed their high accuracy [44].
Baseline co-morbidities were identified according to ICD-9-CM codes, including hypertension, diabetes mellitus, chronic obstructive pulmonary disease, congestive heart failure, chronic liver disease, chronic kidney disease, osteoporosis, malignancy, dementia, depression, epilepsy, and parkinsonism. The overall Charlson comorbidity index was also calculated [45]. The type of Stroke was assigned as per the ICD-9-CM codes for the primary diagnosis during index hospitalization.

The socioeconomic status of the study subjects was approximated using insurance premium and urbanization levels. Insurance premiums, which served as a proxy for income level, were grouped into four categories $(\geq \$ 40,000, \quad \$ 20,000-39,999, \quad \$ 1-19,999$, and fixed amount [New Taiwan dollars]). The incomes of people without salaries such as students, children, elderly, and the unemployed were designated as "fixed amount" (financial dependents), and their insurance premiums were

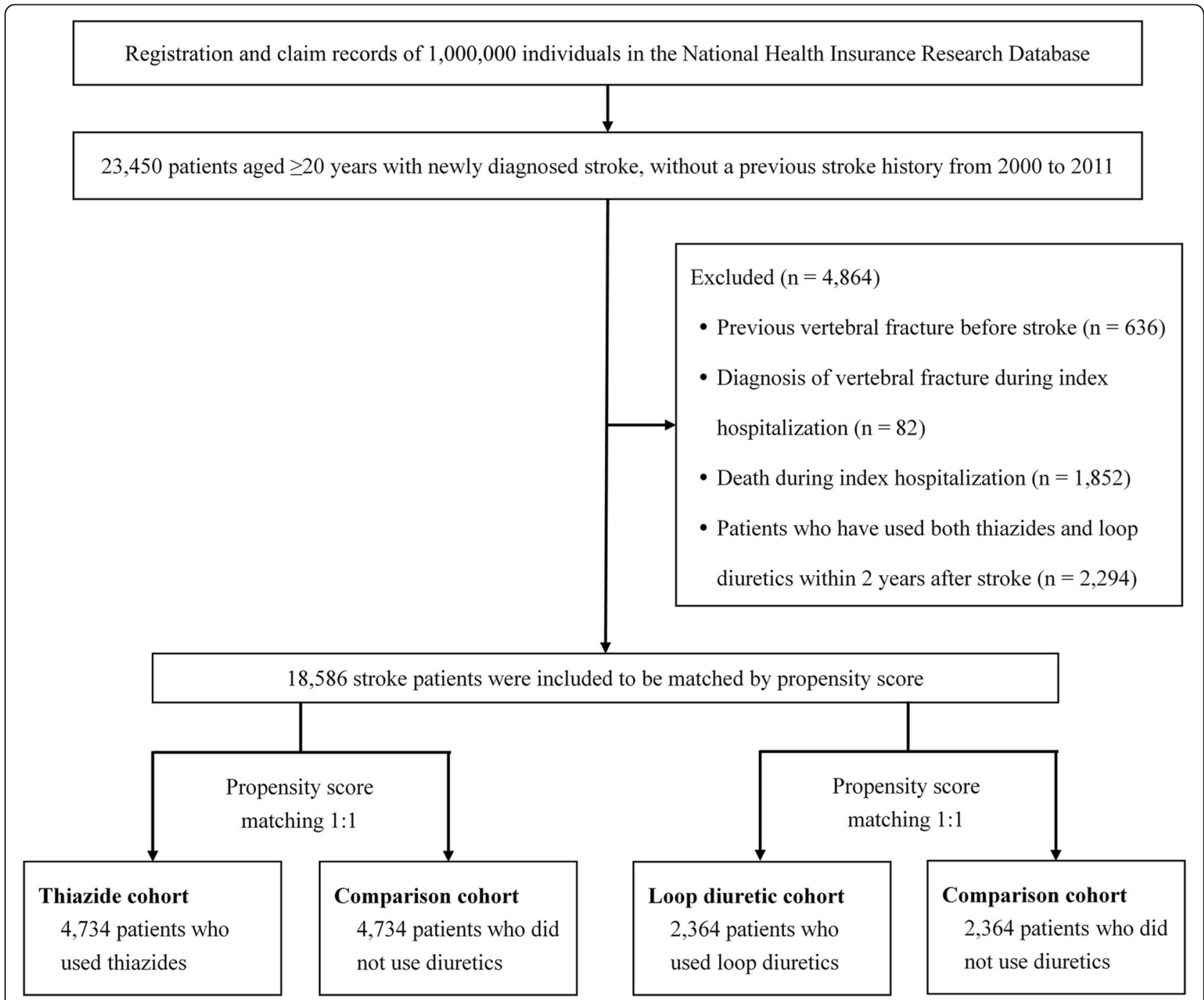

Fig. 1 Flow diagram of the enrollment of the study subjects 
covered by the government or their foster families [46]. Based on information in the NHI research database, subjects were also stratified by residence. Urbanization in Taiwan was categorized into seven levels $[47,48]$, with a lower level indicating a higher degree of urbanization. Levels 5 through 7 were combined into a single group to simplify the analysis [43].

\section{Statistical analysis}

To minimize selection bias, we performed propensity score matching to balance all baseline characteristics listed in Table 1. To analyze the effect of thiazides, we matched patients who received thiazides (thiazide cohort) to those who did not receive diuretics (comparison cohort) in a 1:1 ratio. To analyze the effect of loop diuretics, we matched patients who received loop diuretics (loop diuretic cohort) to those who did not receive diuretics (comparison cohort) in the same ratio. Propensity score matching was conducted without replacement, and the nearest-neighbor algorithm was applied to construct matched pairs.

A $\mathrm{X} 2$ analysis was used to analyze categorical variables in this study. The vertebral fracture-free rates were estimated using the Kaplan-Meier method, and the difference between these survival curves was analyzed using the log-rank test. Univariate and multivariate Cox proportional hazards regression models were used to calculate the incidence rate, hazard ratios (HRs), and 95\% confidence intervals (CIs) of vertebral fracture risk in association with thiazides or loop diuretics. All baseline characteristics listed in Table 1 were adjusted when performing multivariate Cox proportional hazards regression model. Sensitivity analyses were performed to examine whether different exposure durations for thiazides or loop diuretics affected the outcomes. A probability value of $<0.05$ was considered statistically significant. Stata version 13 (Stata Corporation, College Station, Texas, USA) was used to perform all analyses.

\section{Ethics approval and consent to participate}

As the present study used de-identified secondary data, the patients were not directly involved in this study and thus the need for consent was waived. This study was approved by the Tzu-Chi General Hospital Research Ethics Committee (REC No. IRB107-05-C).

\section{Results}

\section{Patient characteristics}

After excluding patients who did not meet the study criteria and performing propensity score matching, 4734 thiazide users were identified as the thiazide cohort, and 4734 patients who did not use diuretics were matched as the comparison cohort to analyze the effects of thiazides. To analyze the effect of loop diuretics, 2364 loop
Table 1 Baseline characteristics of patients with stroke according to thiazide use after propensity score matching

\begin{tabular}{|c|c|c|c|c|c|}
\hline & \multicolumn{4}{|c|}{ Thiazide use } & \multirow{3}{*}{$\begin{array}{l}p \\
\text { value }\end{array}$} \\
\hline & \multicolumn{2}{|c|}{ Yes $(n=4734)$} & \multicolumn{2}{|c|}{ No $(n=4734)$} & \\
\hline & $n$ & $\%$ & $n$ & $\%$ & \\
\hline \multicolumn{5}{|l|}{ Age (years) } & 0.206 \\
\hline$<60$ & 1454 & 30.7 & 1411 & 29.8 & \\
\hline $60-79$ & 2601 & 54.9 & 2684 & 56.7 & \\
\hline$\geq 80$ & 679 & 14.3 & 639 & 13.5 & \\
\hline \multicolumn{5}{|l|}{ Gender } & 0.661 \\
\hline Male & 2776 & 58.6 & 2755 & 58.2 & \\
\hline Female & 1958 & 41.4 & 1979 & 41.8 & \\
\hline \multicolumn{5}{|l|}{ Income level (NTD) } & 0.737 \\
\hline Financially dependent & 1281 & 27.1 & 1312 & 27.7 & \\
\hline $1-19,999$ & 2466 & 52.1 & 2464 & 52.1 & \\
\hline $20,000-39,999$ & 646 & 13.7 & 641 & 13.5 & \\
\hline$\geq 40,000$ & 341 & 7.2 & 317 & 6.7 & \\
\hline \multicolumn{5}{|l|}{ Urbanization level } & 0.809 \\
\hline 1 (Most urbanized) & 1138 & 24.0 & 1148 & 24.3 & \\
\hline 2 & 1242 & 26.2 & 1271 & 26.9 & \\
\hline 3 & 860 & 18.2 & 852 & 18.0 & \\
\hline 4 & 848 & 17.9 & 855 & 18.1 & \\
\hline 5 (Least urbanized) & 646 & 13.7 & 608 & 12.8 & \\
\hline \multicolumn{5}{|l|}{ Stroke type } & 0.918 \\
\hline Ischemic & 2861 & 60.4 & 2864 & 60.5 & \\
\hline Hemorrhagic & 807 & 17.1 & 821 & 17.3 & \\
\hline TIA & 617 & 13.0 & 596 & 12.6 & \\
\hline Others & 449 & 9.5 & 453 & 9.6 & \\
\hline \multicolumn{5}{|l|}{ Charlson comorbidity index } & 0.707 \\
\hline $1-2$ & 2936 & 62.0 & 2957 & 62.5 & \\
\hline $3-4$ & 1338 & 28.3 & 1304 & 27.5 & \\
\hline$\geq 5$ & 460 & 9.7 & 473 & 10.0 & \\
\hline Hypertension & 4268 & 90.2 & 4267 & 90.1 & 0.972 \\
\hline Diabetes mellitus & 1678 & 35.5 & 1663 & 35.1 & 0.747 \\
\hline COPD & 790 & 16.7 & 795 & 16.8 & 0.891 \\
\hline Congestive heart failure & 290 & 6.1 & 298 & 6.3 & 0.733 \\
\hline Chronic liver disease & 417 & 8.8 & 432 & 9.1 & 0.590 \\
\hline Chronic kidney disease & 293 & 6.2 & 294 & 6.2 & 0.966 \\
\hline Osteoporosis & 206 & 4.4 & 215 & 4.5 & 0.654 \\
\hline Malignancy & 214 & 4.5 & 216 & 4.6 & 0.921 \\
\hline Dementia & 202 & 4.3 & 207 & 4.4 & 0.800 \\
\hline Depression & 194 & 4.1 & 191 & 4.0 & 0.876 \\
\hline Epilepsy & 63 & 1.3 & 66 & 1.4 & 0.790 \\
\hline Parkinsonism & 126 & 2.7 & 116 & 2.5 & 0.515 \\
\hline
\end{tabular}

A $\times 2$ test was used to compare the differences between the two groups Abbreviations: NTD New Taiwan dollars, COPD chronic obstructive pulmonary disease, TIA transient ischemic attack 
diuretic users were identified as the loop diuretic cohort, and 2364 non-users comprised the comparison cohort (Fig. 1). There were no significant differences between the groups for all baseline characteristics including age, gender, income level, urbanization level, stroke type, Charlson comorbidity index, and comorbidities after propensity score matching (Table 1 for thiazide use and Table 2 for loop diuretic use).

\section{Thiazide use and vertebral fracture risk}

Kaplan-Meier survival analysis revealed no significant difference in the cumulative incidence of vertebral fracture between the thiazide and comparison cohorts (15.4 per 1000 person-years vs. 13.1 per 1000 person-years, $p=0.201$ ) (Fig. 2a). The HRs of vertebral fracture associated with thiazide use were not significantly different in both univariate (crude $\mathrm{HR}=1.18,95 \% \mathrm{CI}=$ $0.92-1.52, \quad p=0.201)$ and multivariate Cox proportional hazards regression models (adjusted $\mathrm{HR}=1.14$, 95\% CI $=0.88-1.47, p=0.316$ ) (Table 3).

Sensitivity analyses to evaluate the effect of exposure duration within 2 years after stroke revealed that only $1-$ 90 days of thiazide use significantly increased the risk of vertebral fracture compared with non-use (adjusted HR $=1.38,95 \% \mathrm{CI}=1.02-1.88, p=0.039$ ), whereas longer exposure durations had no significant effect. In addition, we observed a trend that estimates of HRs for vertebral fracture tended to be lower as the exposure duration increased (Table 4).

\section{Loop diuretic use and vertebral fracture risk}

The cumulative incidence of vertebral fracture in the loop diuretic cohort was significantly higher than that in the comparison cohort (25.2 per 1000 person-years vs. 17.9 per 1000 person-years, $p=0.031$ ) (Fig. 2b). The HRs also revealed that the loop diuretic cohort had a significantly higher risk of vertebral fracture than the comparison cohort in both univariate (crude $\mathrm{HR}=1.40$, $95 \% \mathrm{CI}=1.03-1.92, p=0.032)$ and multivariate Cox proportional hazards regression models (adjusted $\mathrm{HR}=1.45$, 95\% CI $=1.06-1.98, p=0.019$ ) (Table 3 ).

Sensitivity analyses for the exposure duration revealed that only 1-90 days of loop diuretic use significantly increased the risk of vertebral fracture compared with non-use (adjusted HR $=1.56,95 \% \mathrm{CI}=1.11-2.20, p=0.011$ ). The estimates of HRs for vertebral fracture appeared to decrease as the exposure duration increased, and no significant effect was observed in the two subgroups with longer exposure durations (Table 4).

\section{Discussion}

In this population-based propensity score-matched retrospective cohort study, we found that short-term use of thiazides or loop diuretics after stroke was associated with an
Table 2 Baseline characteristics of patients with stroke according to loop diuretic use after propensity score matching

\begin{tabular}{|c|c|c|c|c|c|}
\hline & \multicolumn{4}{|c|}{ Loop diuretic use } & \multirow{3}{*}{$\begin{array}{l}p \\
\text { value }\end{array}$} \\
\hline & \multicolumn{2}{|c|}{ Yes $(n=2364)$} & \multicolumn{2}{|c|}{ No $(n=2364)$} & \\
\hline & $n$ & $\%$ & $n$ & $\%$ & \\
\hline \multicolumn{5}{|l|}{ Age (years) } & 0.645 \\
\hline$<60$ & 398 & 16.8 & 375 & 15.9 & \\
\hline $60-79$ & 1306 & 55.3 & 1314 & 55.6 & \\
\hline$\geq 80$ & 660 & 27.9 & 675 & 28.5 & \\
\hline \multicolumn{5}{|l|}{ Gender } & 0.792 \\
\hline Male & 1344 & 56.9 & 1335 & 56.5 & \\
\hline Female & 1020 & 43.1 & 1029 & 43.5 & \\
\hline \multicolumn{5}{|l|}{ Income level (NTD) } & 0.215 \\
\hline Financially dependent & 822 & 34.8 & 821 & 34.7 & \\
\hline $1-19,999$ & 1283 & 54.3 & 1323 & 56.0 & \\
\hline $20,000-39,999$ & 188 & 7.9 & 167 & 7.1 & \\
\hline$\geq 40,000$ & 71 & 3.0 & 53 & 2.2 & \\
\hline \multicolumn{5}{|l|}{ Urbanization level } & 0.943 \\
\hline 1 (Most urbanized) & 542 & 22.9 & 541 & 22.9 & \\
\hline 2 & 604 & 25.6 & 612 & 25.9 & \\
\hline 3 & 403 & 17.1 & 402 & 17.0 & \\
\hline 4 & 469 & 19.8 & 449 & 19.0 & \\
\hline 5 (Least urbanized) & 346 & 14.6 & 360 & 15.2 & \\
\hline \multicolumn{5}{|l|}{ Stroke type } & 0.524 \\
\hline Ischemic & 1431 & 60.5 & 1467 & 62.0 & \\
\hline Hemorrhagic & 373 & 15.8 & 380 & 16.1 & \\
\hline TIA & 321 & 13.6 & 298 & 12.6 & \\
\hline Others & 239 & 10.1 & 219 & 9.3 & \\
\hline \multicolumn{5}{|l|}{ Charlson comorbidity index } & 0.415 \\
\hline $1-2$ & 1073 & 45.4 & 1110 & 47.0 & \\
\hline $3-4$ & 774 & 32.7 & 733 & 31.0 & \\
\hline$\geq 5$ & 517 & 21.9 & 521 & 22.0 & \\
\hline Hypertension & 1840 & 77.8 & 1854 & 78.4 & 0.622 \\
\hline Diabetes mellitus & 970 & 41.0 & 976 & 41.3 & 0.859 \\
\hline COPD & 646 & 27.3 & 657 & 27.8 & 0.720 \\
\hline Congestive heart failure & 459 & 19.4 & 427 & 18.1 & 0.233 \\
\hline Chronic liver disease & 299 & 12.7 & 288 & 12.2 & 0.628 \\
\hline Chronic kidney disease & 379 & 16.0 & 355 & 15.0 & 0.335 \\
\hline Osteoporosis & 133 & 5.6 & 133 & 5.6 & 1.000 \\
\hline Malignancy & 190 & 8.0 & 170 & 7.2 & 0.273 \\
\hline Dementia & 169 & 7.1 & 154 & 6.5 & 0.387 \\
\hline Depression & 139 & 5.9 & 128 & 5.4 & 0.488 \\
\hline Epilepsy & 46 & 1.9 & 39 & 1.6 & 0.444 \\
\hline Parkinsonism & 121 & 5.1 & 122 & 5.2 & 0.947 \\
\hline
\end{tabular}

A $\times 2$ test was used to compare the differences between the two groups Abbreviations: NTD New Taiwan dollars, COPD chronic obstructive pulmonary disease, TIA transient ischemic attack 


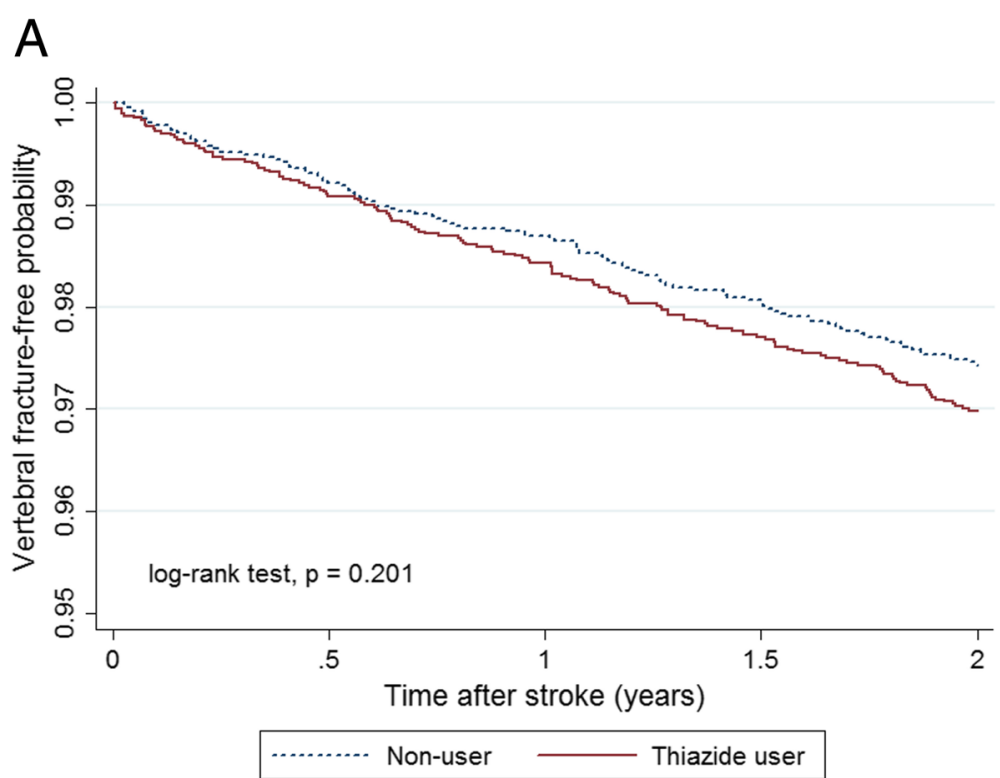

B

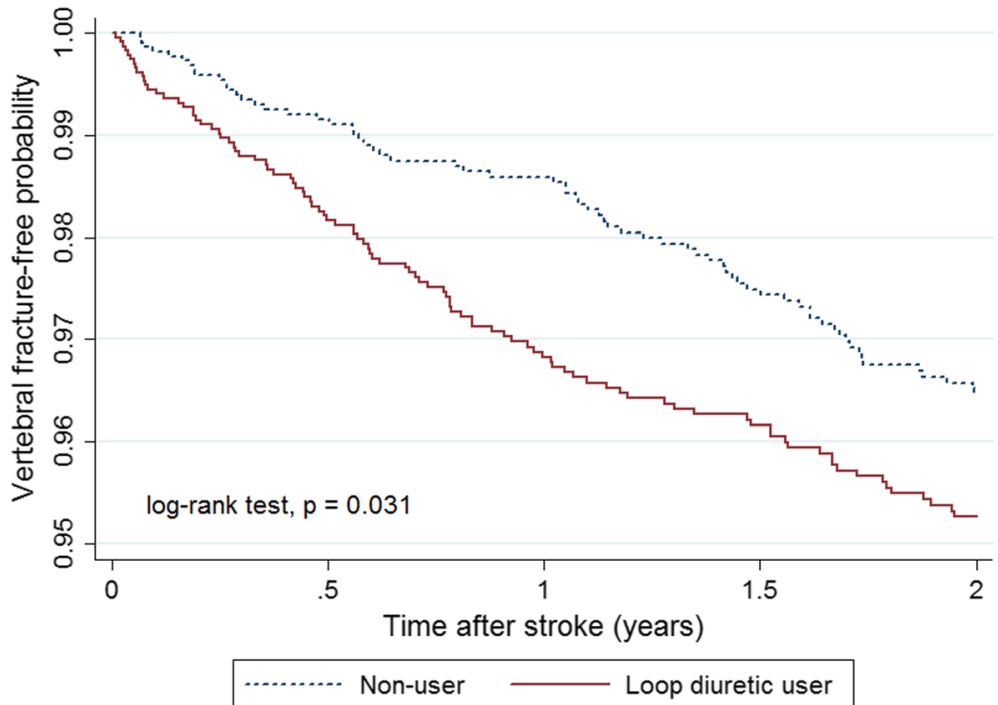

Fig. 2 Kaplan-Meier curves showing estimated vertebral fracture-free probability in post-stroke patients according to diuretic use. a Thiazide user vs. non-user. b Loop diuretic user vs. non-user

increased risk of vertebral fracture. To the best of our knowledge, this is the first study to investigate the association between diuretic use and the risk of vertebral fracture after stroke. Vertebral fracture risk is an important issue to be addressed among patients who use diuretics after stroke because many of these patients receive concurrent hypertension treatment, and stroke is a major risk factor for osteoporosis and fracture [6]. However, the relevant literature was sparse.

The higher vertebral fracture risk associated with thiazide use after stroke was unexpected, although the effect was only linked to short-term use. Previous studies have suggested that thiazide diuretics decrease hip fracture risk $[27,28]$. Few studies have evaluated vertebral fractures, and the results were inconsistent [33, 34, 37]. One previous study, which only included women $\geq 65$ years of age, demonstrated that thiazide use was not identified as a risk or protective factor of vertebral fracture [33]. Another large-scale case-control study in Denmark, which focused on the general population, found that use of thiazides is associated with significantly reduced risks of all fractures, but non-significant results were found for vertebral fractures [34]. However, on sub-analyses after categorizing patients according to cumulative doses, the aforementioned study found a significant higher risk of vertebral fracture in patients who received low cumulative 
Table 3 Risk of vertebral fracture for patients with stroke according to thiazide and loop diuretic use

\begin{tabular}{|c|c|c|c|c|}
\hline & \multicolumn{2}{|l|}{ Thiazide use } & \multicolumn{2}{|l|}{ Loop diuretic use } \\
\hline & Yes $(n=4734)$ & No $(n=4734)$ & Yes $(n=2364)$ & No $(n=2364)$ \\
\hline Cases of vertebral fracture & 138 & 108 & 99 & 67 \\
\hline Person-years & 8975.9 & 8251.3 & 3928.8 & 3740.5 \\
\hline Incidence rate ${ }^{a}$ & 15.4 & 13.1 & 25.2 & 17.9 \\
\hline \multicolumn{5}{|l|}{ Univariate model } \\
\hline crude HR (95\% Cl) & $1.18(0.92-1.52)$ & 1 (ref.) & $1.40(1.03-1.92)$ & 1 (ref.) \\
\hline$p$ value & 0.201 & & 0.032 & \\
\hline \multicolumn{5}{|l|}{ 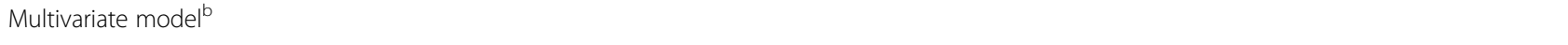 } \\
\hline adjusted HR (95\% Cl) & $1.14(0.88-1.47)$ & 1 (ref.) & $1.45(1.06-1.98)$ & 1 (ref.) \\
\hline$p$ value & 0.316 & & 0.019 & \\
\hline
\end{tabular}

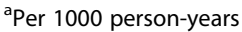

${ }^{\mathrm{b}}$ Multivariate Cox proportional hazard regression model with adjustment for all baseline characteristics shown in Table 1

Abbreviations: $\mathrm{HR}$ hazard ratio, $\mathrm{Cl}$ confidence interval

doses of thiazides. The other two higher-dose categories showed no significant association between thiazide use and vertebral fracture risks [34]. The results seem more compatible with our study results, which revealed that only short-term thiazide use was associated with increased vertebral fracture risks, but such association was not found in those with longer-duration thiazide use. In addition, the other recent large-scale cohort study, which only included female patients, revealed that thiazides and loop diuretics are independently associated with an increased risk of vertebral fracture [37], but this study only categorized subjects into binary categories of diuretic use through questionnaires, without examining the effect of the exposure duration or dose.

Among stroke patients, diuretics were commonly prescribed owing to the high prevalence of hypertension. Stroke patients are at greater risks of developing fracture, and fractures after stroke contribute to further decreased recovery of independent mobility and might cause disability, morbidity, and mortality. Our study, which focused on stroke patients, included homogeneous study subjects and more precise evidence for such a unique and important population. Moreover, our study results clearly indicated only short-term, not long-term, use of thiazides and loop diuretics, which is associated with higher risks of vertebral fractures. This information may cause clinicians and patients to consider and weigh the possible benefits and harmful effects before prescribing diuretics in stroke survivors.

A possible explanation for the increased vertebral fracture risk among thiazide users could be hyponatremia [37], which reportedly develops in approximately $30 \%$ of thiazide users [49]. Thiazide-induced hyponatremia occurred rapidly, appearing within a mean of 19 days after starting treatment [50]. Hyponatremia, even if only mild, might increase the risk of falls and consequent fractures due to gait and attention impairments [51, 52]. In addition, studies revealed that hyponatremia can have direct effects on bone via the activation of osteoclasts [53], which may cause microdamage of bone, resulting in decreased bone quality [54], and a further increased risk of osteoporosis and fracture of the spine because it is particularly susceptible to microdamage relative to other fracture sites $[18,37,55,56]$. However, the sensitivity analyses in this present study revealed no such effect of increased fracture risk in the two subgroups with longer thiazide exposure durations. We should not ignore that thiazides can also modulate calcium homeostasis, which is effective in preserving BMD [16]. However, the effects on BMD take a long time to appear. One study conducted by Bolland et al. evaluated the association of thiazide use and BMD in postmenopausal

Table 4 Adjusted HRs of vertebral fracture according to the duration of use of thiazides and loop diuretics

\begin{tabular}{|c|c|c|c|c|c|c|}
\hline \multirow{2}{*}{$\begin{array}{l}\text { Duration of } \\
\text { use }\end{array}$} & \multicolumn{3}{|l|}{ Thiazides } & \multicolumn{3}{|l|}{ Loop diuretics } \\
\hline & adjusted $H^{a}$ & $95 \% \mathrm{Cl}$ & $p$ value & adjusted $\mathrm{HR}^{\mathrm{a}}$ & $95 \% \mathrm{Cl}$ & $p$ value \\
\hline None & 1 (ref.) & & & 1 (ref.) & & \\
\hline $1-90$ days & 1.38 & $1.02-1.88$ & 0.039 & 1.56 & $1.11-2.20$ & 0.011 \\
\hline 91-365 days & 1.14 & $0.80-1.62$ & 0.470 & 1.32 & $0.81-2.14$ & 0.263 \\
\hline > 365 days & 0.80 & $0.53-1.22$ & 0.298 & 1.23 & $0.66-2.29$ & 0.521 \\
\hline
\end{tabular}

${ }^{a}$ Calculated using a multivariate Cox proportional hazard regression model with adjustment for all baseline characteristics shown in Table 1

Abbreviations: $H R$ hazard ratio, $\mathrm{Cl}$ confidence interval 
women, and the study indicated that the protective effect of thiazides on BMD appeared 6-12 months after treatment initiation [57]. In addition, another study conducted by Kruse et al. indicated that thiazide use was found to increase fracture risk during weeks 1-42 of treatment and then gradually decrease the risk starting from week 43, and this study concluded that a long duration of continuous thiazide exposure is important for obtaining a protective effect on fracture risk [58]. These findings could possibly explain our observation that only short-term thiazide users had higher vertebral fracture risk. When the exposure duration increased, the estimated HRs of vertebral fracture decreased, as shown in Table 4.

The findings of associations between loop diuretic use and increased vertebral fracture risk were expected. However, this is the first study to evaluate the effect in patients who experienced a stroke. The use of loop diuretics was found to increase fracture risk due to several reasons, as mentioned in previous studies. Loop diuretics increased urinary calcium excretion, and they might have promoted higher rates of bone loss and bone porosity $[59,60]$. The drugs might have also potentially caused orthostatic hypotension and fall $[26,61]$, subsequently increasing the risk of fractures [60].

However, the sensitivity analyses revealed that only short-term loop diuretic users had a significantly higher vertebral fracture risk. No such significant effect was found in the two subgroups with longer exposure durations. A previous study focusing on long-term loop diuretic users indicated that increased renal calcium loss after using loop diuretics is compensated by a parathyroid hormone-dependent increase in 1,25-dihydroxyvitamin D levels. Surprisingly, the exposure duration of loop diuretics was positively associated with spinal BMD, which increased by $0.3 \%$ per year of loop diuretic treatment [23]. In addition, Berry et al. indicated that an increased risk of fracture was observed only during the initiation period of diuretics, including both thiazides and loop diuretics, although the study outcome was based on a case of hip fracture. The authors concluded that the hip fracture risk was only transiently elevated after starting the use of loop or thiazide diuretics [30]. Therefore, in addition to the aforementioned reasons, these findings can also explain why only patients with short-term diuretic exposure within 2 years after stroke had a higher fracture risk in analyses of both thiazides and loop diuretics in this present study.

The present study was based on a nationwide population-based design, as all results originated from a representative sample of 1 million subjects randomly selected from the NHI research database in Taiwan. The database provided a sufficient sample size to evaluate the effect of diuretics on vertebral fracture risk, specifically in post-stroke patients. Nevertheless, our study has several limitations that should be mentioned. First, we could not retrieve some clinical data, including patient lifestyles and physical, psychiatric, or laboratory examination data (e.g., BMD, body mass index, smoking status, and alcohol use) from the NHI research database [43], and they might represent confounding factors of fracture risk. Even if we had an adequate study design, including propensity score matching to balance baseline differences between groups and further use of a multivariate Cox proportional hazards regression model to eliminate residual confounding effects, bias related to unknown or unmeasured confounders might still exist. Second, because of using the de-identified secondary data, we could not directly approach the patients to monitor the exact intake of diuretics or other medications. We also could not identify the exact mechanism of how the vertebral fracture occurred to distinguish whether the fracture was caused by osteoporosis or a trauma event. Third, because of the patient anonymity policy in the NHI research database, we could not confirm the accuracy of the patients' diagnoses by contacting the patients directly [43]. We also could not obtain the detailed image reports in the claims-based dataset; thus, we could not determine what types of image and how such image examination confirmed the vertebral fracture. However, the subjects who developed stroke were identified only when they were hospitalized with a primary diagnosis of stroke. In addition, the ICD-9-CM codes for the diagnosis of vertebral fracture were validated in a previous study, and they displayed high accuracy in both inpatients and outpatient service [44]. Moreover, hospitals or physicians in Taiwan would be heavily fined for incorrect diagnoses or coding [62]. Thus, the validity of the diagnoses of stroke and vertebral fracture should be considered acceptable.

\section{Conclusions}

In summary, this population-based propensity scorematched retrospective cohort study indicated that short-term thiazide or loop diuretic treatment was associated with an increased risk of vertebral fracture in post-stroke patients. Patients and clinicians should keep this association in mind and consider and weigh the possible benefits and harm of diuretics before prescribing diuretics in stroke survivors. Further prospective clinical trials are required to confirm this finding.

\footnotetext{
Abbreviations

BMD: Bone mineral density; Cl: Confidence interval; COPD: Chronic obstructive pulmonary disease; HR: Hazard ratio; ICD-9-CM: International Classification of Diseases, 9th Revision, Clinical Modification; LHID: Longitudinal Heath Insurance Database; NHI: National Health Insurance; NHRI: National Health Research Institute; TIA: Transient ischemic attack
}

Acknowledgements

None. 


\section{Funding}

The authors received no specific funding for this study.

\section{Availability of data and materials}

Requests for data can be sent as a formal proposal to the National Health Research Institute of Taiwan (http://nhird.nhri.org.tw) or by email to nhird@nhri.org.tw

\section{Authors' contributions}

SML and HKH conceptualized the study. SHY obtained the research database. SML, CYW, and HKH drafted the manuscript. SML, CYW, SHY, and HKH analyzed and interpreted the data. SML, CYW, SHY, and HKH revised the manuscript for intellectual content. All authors have read and approved the manuscript.

\section{Ethics approval and consent to participate}

This study was approved by the Institutional Review Board of Tzu Chi Medical Center (REC No.: IRB104-131C). The requirement for participant consent was waived owing to the retrospective nature of this study using de-identified secondary data.

\section{Consent for publication}

Not applicable.

\section{Competing interests}

The authors declare that they have no competing interests.

\section{Publisher's Note}

Springer Nature remains neutral with regard to jurisdictional claims in published maps and institutional affiliations.

\section{Author details}

${ }^{1}$ Department of Physical Medicine and Rehabilitation, Buddhist Tzu Chi General Hospital, No. 707, Sec. 3, Chung Yang Rd., Hualien 97002, Taiwan. ${ }^{2}$ School of Medicine, Tzu Chi University, No.701, Sec. 3, Chung Yang Rd., Hualien 97002, Taiwan. ${ }^{3}$ Department of Family Medicine, Buddhist Tzu Chi General Hospital, No. 707, Sec. 3, Chung Yang Rd., Hualien 97002, Taiwan.

\section{Received: 5 January 2018 Accepted: 20 February 2019}

\section{Published online: 04 March 2019}

\section{References}

1. Riggs $B L$, Melton $L J$ 3rd. The worldwide problem of osteoporosis: insights afforded by epidemiology. Bone. 1995;17(5 Suppl):505S-11S.

2. Waterloo S, Ahmed LA, Center JR, Eisman JA, Morseth B, Nguyen ND, Nguyen T, Sogaard AJ, Emaus N. Prevalence of vertebral fractures in women and men in the population-based Tromso study. BMC Musculoskelet Disord. 2012:13:3.

3. Hasserius R, Karlsson MK, Jonsson B, Redlund-Johnell I, Johnell O. Long-term morbidity and mortality after a clinically diagnosed vertebral fracture in the elderly--a 12- and 22-year follow-up of 257 patients. Calcif Tissue Int. 2005; 76(4):235-42.

4. Nevitt MC, Ettinger B, Black DM, Stone K, Jamal SA, Ensrud K, Segal M, Genant HK, Cummings SR. The association of radiographically detected vertebral fractures with back pain and function: a prospective study. Ann Intern Med. 1998;128(10):793-800

5. Kado DM, Browner WS, Palermo L, Nevitt MC, Genant HK, Cummings SR Vertebral fractures and mortality in older women: a prospective study. Study of osteoporotic fractures research group. Arch Intern Med. 1999:159(11): 1215-20.

6. Carda S, Cisari C, Invernizzi M, Bevilacqua M. Osteoporosis after stroke: a review of the causes and potential treatments. Cerebrovasc Dis. 2009;28(2): $191-200$.

7. Jorgensen L, Engstad T, Jacobsen BK. Bone mineral density in acute stroke patients: low bone mineral density may predict first stroke in women. Stroke. 2001;32(1):47-51

8. Sato $Y$, Kuno H, Kaji M, Etoh K, Oizumi K. Influence of immobilization upon calcium metabolism in the week following hemiplegic stroke. J Neurol Sci. 2000;175(2):135-9.

9. Dennis MS, Lo KM, McDowall M, West T. Fractures after stroke: frequency, types, and associations. Stroke. 2002;33(3):728-34.
10. Kapral MK, Fang J, Alibhai SM, Cram P, Cheung AM, Casaubon LK, Prager M, Stamplecoski M, Rashkovan B, Austin PC. Risk of fractures after stroke: results from the Ontario stroke registry. Neurology. 2017;88(1):57-64.

11. Hsieh Fl, Chiou HY. Stroke: morbidity, risk factors, and care in Taiwan. J Stroke. 2014;16(2):59-64

12. Hsieh Fl, Lien LM, Chen ST, Bai CH, Sun MC, Tseng HP, Chen YW, Chen $\mathrm{CH}_{\text {, }}$ Jeng JS, Tsai SY, et al. Get with the guidelines-stroke performance indicators: surveillance of stroke care in the Taiwan stroke registry: get with the guidelines-stroke in Taiwan. Circulation. 2010;122(11):1116-23.

13. Musini VM, Nazer M, Bassett K, Wright JM. Blood pressure-lowering efficacy of monotherapy with thiazide diuretics for primary hypertension. Cochrane Database Syst Rev. 2014;5:CD003824.

14. Blowey DL. Diuretics in the treatment of hypertension. Pediatr Nephrol. 2016;31(12):2223-33.

15. Kaufman DW, Kelly JP, Rosenberg L, Anderson TE, Mitchell AA. Recent patterns of medication use in the ambulatory adult population of the United States: the Slone survey. JAMA. 2002;287(3):337-44.

16. LaCroix AZ, Ott SM, Ichikawa L, Scholes D, Barlow WE. Low-dose hydrochlorothiazide and preservation of bone mineral density in older adults. A randomized, double-blind, placebo-controlled trial. Ann Intern Med. 2000;133(7):516-26.

17. Dvorak MM, De Joussineau C, Carter DH, Pisitkun T, Knepper MA, Gamba G, Kemp PJ, Riccardi D. Thiazide diuretics directly induce osteoblast differentiation and mineralized nodule formation by interacting with a sodium chloride co-transporter in bone. J Am Soc Nephrol. 2007;18(9):2509-16.

18. Hoorn EJ, Rivadeneira F, van Meurs JB, Ziere G, Stricker BH, Hofman A, Pols HA, Zietse $R$, Uitterlinden AG, Zillikens MC: Mild hyponatremia as a risk factor for fractures: the Rotterdam study. J Bone Miner Res 2011, 26(8):1822-1828.

19. Kinsella S, Moran S, Sullivan MO, Molloy MG, Eustace JA. Hyponatremia independent of osteoporosis is associated with fracture occurrence. Clin J Am Soc Nephrol. 2010;5(2):275-80.

20. Usala RL, Fernandez SJ, Mete M, Cowen L, Shara NM, Barsony J, Verbalis JG. Hyponatremia is associated with increased osteoporosis and bone fractures in a large US health system population. J Clin Endocrinol Metab. 2015; 100(8):3021-31.

21. Jamal SA, Arampatzis S, Harrison SL, Bucur RC, Ensrud K, Orwoll ES, Bauer DC. Hyponatremia and fractures: findings from the MrOS study. J Bone Miner Res. 2015:30(6):970-5.

22. Friedman PA, Bushinsky DA. Diuretic effects on calcium metabolism. Semin Nephrol. 1999:19(6):551-6.

23. Rejnmark L, Vestergaard P, Heickendorff L, Andreasen F, Mosekilde L. Effects of long-term treatment with loop diuretics on bone mineral density, calcitropic hormones and bone turnover. J Intern Med. 2005;257(2):176-84

24. Rejnmark L, Vestergaard P, Heickendorff L, Andreasen F, Mosekilde L. Loop diuretics increase bone turnover and decrease BMD in osteopenic postmenopausal women: results from a randomized controlled study with bumetanide. J Bone Miner Res. 2006:21(1):163-70.

25. Lim LS, Fink HA, Kuskowski MA, Taylor BC, Schousboe JT, Ensrud KE. Loop diuretic use and increased rates of hip bone loss in older men: the osteoporotic fractures in men study. Arch Intern Med. 2008;168(7):735-40

26. Okada K, Okada M, Kamada N, Yamaguchi Y, Kakehashi M, Sasaki H, Katoh S, Morita K. Reduction of diuretics and analysis of water and muscle volumes to prevent falls and fall-related fractures in older adults. Geriatr Gerontol Int 2017;17(2):262-9.

27. Aung K, Htay $T$. Thiazide diuretics and the risk of hip fracture. Cochrane Database Syst Rev. 2011;10:CD005185.

28. Puttnam R, Davis BR, Pressel SL, Whelton PK, Cushman WC, Louis GT, Margolis KL, Oparil S, Williamson J, Ghosh A, et al. Association of 3 different antihypertensive medications with hip and pelvic fracture risk in older adults: secondary analysis of a randomized clinical trial. JAMA Intern Med. 2017;177(1):67-76

29. Corrao G, Mazzola P, Monzio Compagnoni M, Rea F, Merlino L, Annoni G, Mancia G. Antihypertensive Medications, Loop Diuretics, and Risk of hip fracture in the elderly: a population-based cohort study of 81,617 Italian patients newly treated between 2005 and 2009. Drugs Aging. 2015;32(11): 927-36.

30. Berry SD, Zhu Y, Choi H, Kiel DP, Zhang Y. Diuretic initiation and the acute risk of hip fracture. Osteoporos Int. 2013;24(2):689-95.

31. Schoofs MW, van der Klift M, Hofman A, de Laet CE, Herings RM, Stijnen T, Pols HA, Stricker BH. Thiazide diuretics and the risk for hip fracture. Ann Intern Med. 2003;139(6):476-82 
32. LaCroix AZ, Wienpahl J, White LR, Wallace RB, Scherr PA, George LK, Cornoni-Huntley J, Ostfeld AM. Thiazide diuretic agents and the incidence of hip fracture. N Engl J Med. 1990;322(5):286-90.

33. Nevitt MC, Cummings SR, Stone KL, Palermo L, Black DM, Bauer DC, Genant HK, Hochberg MC, Ensrud KE, Hillier TA, et al. Risk factors for a first-incident radiographic vertebral fracture in women $>$ or $=65$ years of age: the study of osteoporotic fractures. J Bone Miner Res. 2005;20(1):131-40.

34. Rejnmark $L$, Vestergaard $P$, Mosekilde $L$. Reduced fracture risk in users of thiazide diuretics. Calcif Tissue Int. 2005;76(3):167-75.

35. Rejnmark $L$, Vestergaard $P$, Mosekilde $L$. Fracture risk in patients treated with loop diuretics. J Intern Med. 2006;259(1):117-24.

36. Carbone LD, Johnson KC, Bush AJ, Robbins J, Larson JC, Thomas A, LaCroix AZ. Loop diuretic use and fracture in postmenopausal women: findings from the Women's Health Initiative. Arch Intern Med. 2009;169(2):132-40.

37. Paik JM, Rosen HN, Gordon CM, Curhan GC. Diuretic use and risk of vertebral fracture in women. Am J Med. 2016;129(12):1299-306.

38. Wu TY, Majeed A, Kuo KN. An overview of the healthcare system in Taiwan. London J Prim Care (Abingdon). 2010;3(2):115-9.

39. Chou YC, Liao CC, Su LT, Yang PY, Sung FC. Stroke rehabilitation is associated with a reduction in dementia risk: a population-based retrospective cohort study. J Rehabil Med. 2012;44(4):319-24.

40. Chen YJ, Chang YT, Wang CB, Wu CY. The risk of cancer in patients with rheumatoid arthritis: a nationwide cohort study in Taiwan. Arthritis Rheum. 2011;63(2):352-8.

41. Tsan $Y T$, Lee $\mathrm{CH}$, Wang JD, Chen PC. Statins and the risk of hepatocellular carcinoma in patients with hepatitis B virus infection. J Clin Oncol. 2012; 30(6):623-30.

42. Lin SM, Yang SH, Liang CC, Huang HK. Proton pump inhibitor use and the risk of osteoporosis and fracture in stroke patients: a population-based cohort study. Osteoporos Int. 2018;29(1):153-62.

43. Lin SM, Yang SH, Cheng HY, Liang CC, Huang HK. Thiazide diuretics and the risk of hip fracture after stroke: a population-based propensity-matched cohort study using Taiwan's National Health Insurance Research Database. BMJ Open. 2017;7(9):e016992.

44. Wang WJ, Chao CT, Huang YC, Wang CY, Chang CH, Huang TM, Lai CF, Huang HY, Shiao CC, Chu TS, et al. The impact of acute kidney injury with temporary dialysis on the risk of fracture. J Bone Miner Res. 2014;29(3):676-84.

45. Charlson ME, Pompei P, Ales KL, Mackenzie CR. A new method of classifying prognostic comorbidity in longitudinal studies: development and validation. J Chronic Dis. 1987:40(5):373-83.

46. Wu JC, Liu L, Wen-Cheng H, Chen YC, Ko CC, Wu CL, Chen TJ, Cheng H, Su TP. The incidence of adjacent segment disease requiring surgery after anterior cervical diskectomy and fusion: estimation using an 11-year comprehensive nationwide database in Taiwan. Neurosurgery. 2012;70(3): 594-601.

47. Lin HC, Chao PZ, Lee HC. Sudden sensorineural hearing loss increases the risk of stroke: a 5-year follow-up study. Stroke. 2008;39(10):2744-8.

48. Liu CYHY, Chuang YL, Chen YJ, Weng WS, KY LJSL. Incorporating development stratification of Taiwan townships into sampling design of large scale health interview survey (in Chinese). J Health Manag. 2006;4(1):1-22.

49. Leung AA, Wright A, Pazo V, Karson A, Bates DW. Risk of thiazide-induced hyponatremia in patients with hypertension. Am J Med. 2011;124(11):1064-72.

50. Barber J, McKeever TM, McDowell SE, Clayton JA, Ferner RE, Gordon RD, Stowasser M, O'Shaughnessy KM, Hall IP, Glover M. A systematic review and meta-analysis of thiazide-induced hyponatraemia: time to reconsider electrolyte monitoring regimens after thiazide initiation? $\mathrm{Br} J \mathrm{Clin}$ Pharmacol. 2015;79(4):566-77.

51. Renneboog B, Musch W, Vandemergel X, Manto MU, Decaux G. Mild chronic hyponatremia is associated with falls, unsteadiness, and attention deficits. Am J Med. 2006;119(1):71 e71-78.

52. Gankam Kengne F, Andres C, Sattar L, Melot C, Decaux G. Mild hyponatremia and risk of fracture in the ambulatory elderly. QJM. 2008;101(7):583-8.

53. Hoorn EJ, Liamis G, Zietse R, Zillikens MC. Hyponatremia and bone: an emerging relationship. Nat Rev Endocrinol. 2011;8(1):33-9.

54. Seeman E, Delmas PD. Bone quality--the material and structural basis of bone strength and fragility. N Engl J Med. 2006;354(21):2250-61.

55. Kruse C, Eiken P, Vestergaard P. Hyponatremia and osteoporosis: insights from the Danish National Patient Registry. Osteoporos Int. 2015;26(3):1005-16.

56. Seref-Ferlengez Z, Kennedy OD, Schaffler MB. Bone microdamage, remodeling and bone fragility: how much damage is too much damage? Bonekey Rep. 2015;4:644.
57. Bolland MJ, Ames RW, Horne AM, Orr-Walker BJ, Gamble GD, Reid IR. The effect of treatment with a thiazide diuretic for 4 years on bone density in normal postmenopausal women. Osteoporos Int. 2007;18(4):479-86.

58. Kruse C, Eiken $\mathrm{P}$, Vestergaard $\mathrm{P}$. Continuous and long-term treatment is more important than dosage for the protective effect of thiazide use on bone metabolism and fracture risk. J Intern Med. 2016;279(1):110-22.

59. Rejnmark L, Vestergaard P, Pedersen AR, Heickendorff L, Andreasen F, Mosekilde $L$. Dose-effect relations of loop- and thiazide-diuretics on calcium homeostasis: a randomized, double-blinded Latin-square multiple cross-over study in postmenopausal osteopenic women. Eur J Clin Investig. 2003;33(1): $41-50$.

60. Xiao F, Qu X, Zhai Z, Jiang C, Li H, Liu X, Ouyang Z, Gu D. Association between loop diuretic use and fracture risk. Osteoporos Int. 2015;26(2):775-84.

61. Poon IO, Braun U. High prevalence of orthostatic hypotension and its correlation with potentially causative medications among elderly veterans. J Clin Pharm Ther. 2005;30(2):173-8.

62. Harnod T, Wang YC, Kao CH. Association of Migraine and Sleep-Related Breathing Disorder: a population-based cohort study. Medicine (Baltimore). 2015;94(36):e1506

\section{Ready to submit your research? Choose BMC and benefit from:}

- fast, convenient online submission

- thorough peer review by experienced researchers in your field

- rapid publication on acceptance

- support for research data, including large and complex data types

- gold Open Access which fosters wider collaboration and increased citations

- maximum visibility for your research: over $100 \mathrm{M}$ website views per year

At BMC, research is always in progress.

Learn more biomedcentral.com/submissions 